\title{
Definition of global and transcript-specific mRNA export pathways in metazoans
}

\author{
Natalie G. Farny, ${ }^{1}$ Jessica A. Hurt, ${ }^{1}$ and Pamela A. Silver ${ }^{2}$ \\ Department of Systems Biology, Harvard Medical School, Boston, Massachusetts 02115, USA
}

Eukaryotic gene expression requires export of messenger RNAs (mRNAs) from their site of transcription in the nucleus to the cytoplasm where they are translated. While mRNA export has been studied in yeast, the complexity of gene structure and cellular function in metazoan cells has likely led to increased diversification of these organisms' export pathways. Here we report the results of a genome-wide RNAi screen in which we identify 72 factors required for polyadenylated [poly- $\left.\left(\mathbf{A}^{+}\right)\right]$mRNA export from the nucleus in Drosophila cells. Using structural and functional conservation analysis of yeast and Drosophila mRNA export factors, we expose the evolutionary divergence of eukaryotic mRNA export pathways. Additionally, we demonstrate the differential export requirements of two endogenous heat-inducible transcripts-intronless heat-shock protein 70 (HSP70) and intron-containing HSP83-and identify novel export factors that participate in HSP83 mRNA splicing. We characterize several novel factors and demonstrate their participation in interactions with known components of the Drosophila export machinery. One of these factors, Drosophila melanogaster PCI domain-containing protein 2 (dmPCID2), associates with polysomes and may bridge the transition between exported messenger ribonucleoprotein particles (mRNPs) and polysomes. Our results define the global network of factors involved in Drosophila mRNA export, reveal specificity in the export requirements of different transcripts, and expose new avenues for future work in mRNA export.

[Keywords: mRNA export; Drosophila; RNAi screen; PCID2]

Supplemental material is available at http://www.genesdev.org.

Received September 14, 2007; revised version accepted October 30, 2007.

Transport of messenger RNA (mRNA) from the nucleus to the cytoplasm is a complex and evolutionarily conserved process, essential for gene expression in all eukaryotic cells. Prior to export, an mRNA must be transcribed and undergo myriad processing steps, including 5 '-capping, 3'-processing, splicing, and surveillance, to produce a mature messenger ribonucleoprotein particle (mRNP) competent for translation in the cytoplasm. A cell must continuously distinguish mature mRNPs from the multitude of messages at intermediate stages of biogenesis. To manage this problem, the cell has devised a complex system of physical and functional coupling interactions between factors critical to each processing event and export. Factors required for mRNA export include those that interact with transcripts as they exit the nucleus, and those critical for the proper processing of the transcript so that it may be recognized later in the export pathway. Thus the cell ensures the export of only properly assembled mRNPs and ultimately regulates its

\footnotetext{
${ }^{1}$ These authors contributed equally to this work.

${ }^{2}$ Corresponding author.

E-MAIL pamela_silver@hms.harvard.edu; FAX (617) 432-6405.

Article published online ahead of print. Article and publication date are online at http://www.genesdev.org/cgi/doi/10.1101/gad.1616008.
}

gene expression program (for reviews, see Reed 2003; Vasudevan and Peltz 2003; Vinciguerra and Stutz 2004; Aguilera 2005; Reed and Cheng 2005; Saguez et al. 2005; Sommer and Nehrbass 2005).

Exemplifying the coupling network, mRNA export is linked to transcription and splicing through the recruitment of export machinery directly to these processing sites. Most mRNA export events are mediated by heterodimers of the essential export factors NXF1 (human TAP/yeast Mex67p) and p15 (human NXT1/yeast Mtr2p) (Segref et al. 1997; Tan et al. 2000; Herold et al. 2001). These heterodimers escort competent mRNPs out of the nucleus through interactions with components of the nuclear pore complex (NPC) (Strasser et al. 2000; Wiegand et al. 2002). However, NXF1/p15 heterodimers have a low affinity for binding mRNA (Braun et al. 1999) and require adaptor proteins, such as REF (human Aly/yeast Yralp), to interface with the elongating mRNA strands (Strasser and Hurt 2000; Stutz et al. 2000). In yeast, Yralp is an essential mRNA export factor that is able to interact with mRNA transcripts via interactions with the splicing factor Sub2p (fly/human UAP56) (Strasser and Hurt 2001). Yralp and Sub2p are members of the conserved TREX complex that couples transcription and 
splicing to export (Reed and Cheng 2005). However, while Yralp is an essential factor in yeast, REF is not essential for mRNA export in metazoan cells (Gatfield and Izaurralde 2002; Longman et al. 2003). Whether this difference indicates the existence of other factors with redundant functions to those of Aly and REF, or that a different set of adaptor factors specific to the needs of the Drosophila genome connects the processes of transcription, splicing, and export, remains to be determined.

Evidence has also emerged demonstrating that mRNA export is coupled not only to nuclear processing events, but also to the cytoplasmic events of translation. For example, the shuttling serine arginine rich (SR) adaptor proteins remain associated with translation complexes in the cytoplasm and stimulate the translation of mRNA (Sanford et al. 2004; Windgassen et al. 2004; Swartz et al. 2007). In yeast, translational termination events require the helicase activity of a known RNA export factor, Dbp5p (Gross et al. 2007). Given the high degree of interconnectedness that exists between mRNP assembly and mRNA export, it seems probable that a similar degree of coordination exists with events following the export process. Yet, very little is known, particularly in metazoan cells, about the mechanisms by which export and translation are linked.

Large-scale screens in yeast have yielded most of our current understanding of the requirements for mRNA export. These studies, while seminal to our fundamental knowledge of export, were limited in their scope to libraries of nonessential gene knockouts and temperaturesensitive mutants (Amberg et al. 1992; Brown et al. 1995; Heath et al. 1995; Azad et al. 1997; Hieronymus et al. 2004). Several investigations into the requirement of Drosophila and human homologs of known yeast export factors in the mRNA export pathways of these organisms have been conducted on a small scale (van Deursen et al. 1996; Watkins et al. 1998; Gatfield et al. 2001; Guzik et al. 2001; Herold et al. 2001). However, the complement of factors necessary for mRNA export in higher eukaryotes currently remains poorly defined at a systems-wide level.

The increase in complexity of higher eukaryotic genomes compared with that of yeast is likely to have resulted in a commensurate increase in mRNA export network complexity. For example, while $80 \%$ of Drosophila genes contain introns, only $5 \%$ of Saccharomyces cerevisiae genes are intron-containing (Sakharkar and Kangueane 2004). To accommodate these additional mRNA processing demands, mRNA export pathways of higher eukaryotes are likely to have gained components and/or evolved components to harbor multiple functions. Indeed a number of other adapter proteins that function in a manner similar to REF, such as SR proteins, exist in higher eukaryotes (Huang et al. 2003). Similarly, URH49, an RNA helicase with $90 \%$ identity to and seemingly similar functions to UAP56, has been found (Kapadia et al. 2006). It is currently unknown to what degree the evolution of the genome has affected the Drosophila mRNA export pathway.

In order to define the mRNA export pathway of a metazoan organism on a systems-level scale, we conducted a genome-wide RNAi screen for export factors in Drosophila. Using fluorescent in situ hybridization (FISH), we visually identified 72 factors whose depletion resulted in a nuclear accumulation of polyadenylated [poly- $\left.\left(\mathrm{A}^{+}\right)\right]$mRNA in $\mathrm{S}^{2} \mathrm{R}^{+}$cells. These factors include previously uncharacterized Drosophila proteins and members of the translational machinery, in addition to mRNA processing factors and known export factors. In total, 52 of the factors identified have not been implicated previously in the mRNA export pathway in Drosophila. Comparison of our results with those of systematic yeast studies revealed significant divergence of mRNA export requirements between single-celled eukaryotes and higher metazoans. We identified differences in the export requirements of an intronless and an intron-containing transcript. Additionally, we were able to demonstrate that several of our new mRNA export factors have physical and functional interactions with core export machinery. Finally, we found one of these factors, a homolog of human PCI domain-containing protein 2 (PCID2), associates not only with NXF1 but also with actively translating complexes, thus providing evidence of an additional link between translational machinery and export.

\section{Results}

A genome-wide RNAi screen defines essential mRNA export factors

To obtain a comprehensive understanding of mRNA export pathways in a metazoan system, we performed a genome-wide RNAi screen in Drosophila S2R ${ }^{+}$cells (Kiger et al. 2003; Boutros et al. 2004; Armknecht et al. 2005). Figure 1A summarizes the visual assay used to screen a library of $\sim 21,300$ dsRNAs in duplicate for defects in mRNA export from the nucleus. mRNA export defects were identified based on the subcellular relocalization of poly- $\left(\mathrm{A}^{+}\right)$mRNA in dsRNA-treated cells. Steady-state poly- $\left(\mathrm{A}^{+}\right)$mRNA localization in untreated or control GFP dsRNA-treated $\mathrm{S} \mathrm{R}^{+}$cells is predominantly cytoplasmic (Fig. 1A, left image). Upon treatment with dsRNAs targeting NXF1, an essential mRNA export factor (Katahira et al. 1999; Herold et al. 2001), poly$\left(\mathrm{A}^{+}\right)$mRNA accumulates within the nucleus while being excluded from the nucleolus (Fig. 1A, right image). Using this assay, 133 dsRNAs from the primary screen library scored positive for mRNA export defects. Positive dsRNAs with more than 10 potential off-target effects (Kulkarni et al. 2006) — as defined by complementarity of 21 or more consecutive base pairs with another gene (29 genes), or that have since been removed from the updated version of the dsRNA library (16 genes)-were eliminated from further analysis. The remaining 88 candidate genes were rescreened in duplicate using the same assay with a set of independent, nonoverlapping dsRNAs, all of which have no predicted off-target effects. A total of 72 genes $(82 \%)$ were validated as poly- $\left(\mathrm{A}^{+}\right)$ 


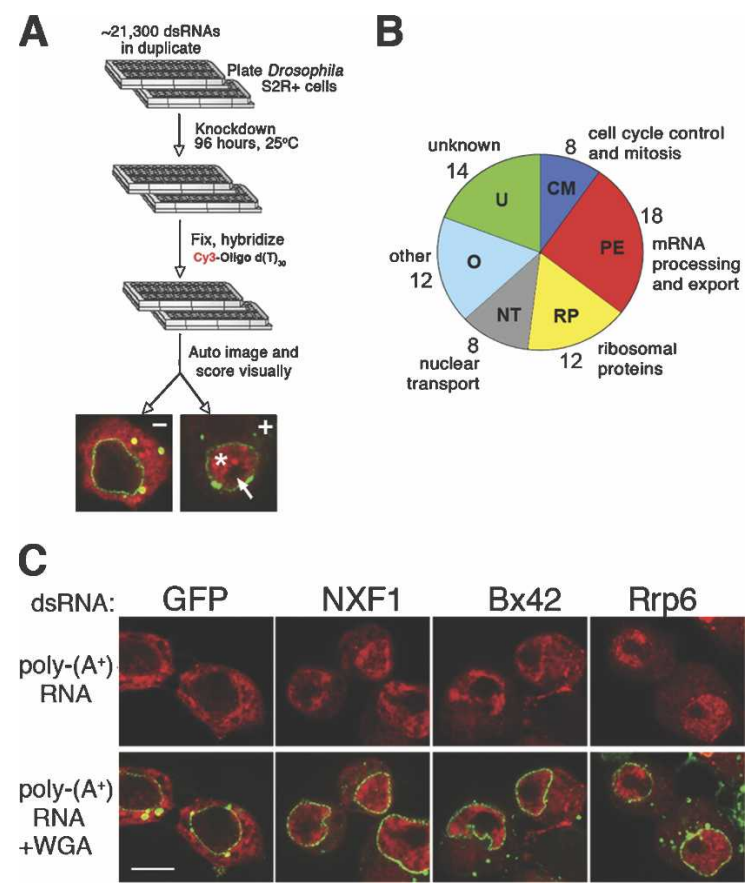

Figure 1. Identification and classification of genes affecting mRNA export in Drosophila S2R ${ }^{+}$cells. (A) A library of $\sim 21,300$ dsRNAs was arrayed in black, clear-bottomed 384-well plates. $\mathrm{S} \mathrm{R}^{+}$cells were plated on these dsRNAs, incubated for $4 \mathrm{~d}$, then fixed and assayed for localization of poly- $\left(\mathrm{A}^{+}\right)$RNA using a Cy3labeled Oligo-d $(T)_{30}$ probe. Images were collected by automated microscopy and visually inspected for nuclear accumulation of poly- $\left(\mathrm{A}^{+}\right)$RNA. Images were scored negative (left image) or positive (right image) for nuclear poly- $\left(\mathrm{A}^{+}\right) \mathrm{RNA}$ accumulation. In positive cells, mRNA accumulates in the nucleus (asterisk) and is excluded from the nucleolus (arrow). (B) Gene ontology categories of the 72 mRNA export factors identified in this screen. $(C)$ The cells shown were treated with dsRNAs for $4 \mathrm{~d}$, targeting the genes indicated. After fixation and hybridization, poly- $\left(\mathrm{A}^{+}\right)$ RNA localization (red, top panels) was determined by overlaying images with the nuclear membrane marker, wheat germ agglutinin (WGA) (green, bottom images). Bar, 4 m.

mRNA export factors and are listed in Supplemental Table S1. Many previously confirmed Drosophila mRNA export factors including NXF1 (Fig. 1C), p15, UAP56, Ssrp, Tho2, and Hrp1 (Gatfield et al. 2001; Herold et al. 2003; Rehwinkel et al. 2004) were recovered during this screen, as were the transcription and splicing factor $\mathrm{Bx} 42$ and the nuclear exosome component Rrp6 (Fig. 1C), neither of which were shown previously to affect mRNA export in Drosophila cells.

To categorize our panel of 72 mRNA export factors, we analyzed their known or hypothetical functions using FlyBase (http://www.flybase.org). Classification by gene ontology $(\mathrm{GO})$ of these factors (Fig. 1B) revealed that many are known to function within mRNA processing or export pathways (PE, 25\%) or protein nuclear transport (NT, $11 \%)$, thereby validating our assay. Protein components of both the large and small ribosomal subunits were found to affect significantly mRNA export $(\mathrm{RP}, 17 \%)$, as were factors involved in cell cycle control and mitosis $(\mathrm{CM}, 11 \%)$. Finally, 14 of the 72 factors identified (U, 19\%) have no annotated gene function in Drosophila.

\section{Comparison of eukaryotic mRNA export pathways reveals evolutionary conservation and divergence}

To place our results in an evolutionary perspective, we compared our screen results with those of previous yeast export studies (Amberg et al. 1992; Brown et al. 1995; Heath et al. 1995; Azad et al. 1997; Hieronymus et al. 2004) so as to reveal the evolutionary divergence of mRNA export pathways between unicellular eukaryotes and metazoan cells. Unlike yeast genes, the majority of metazoan genes contain multiple introns that require extensive processing and regulation. Thus we were interested in assessing how such changes in mRNA processing requirements were reflected in an organism's essential export machinery. Supplemental Table S2 lists 45 $S$. cerevisiae mRNA export factors collected from the literature and their 39 respective Drosophila homologs as determined using the eukatyotic orthology YOGY tool (http://www.sanger.ac.uk/PostGenomics/S_pombe/ YOGY; Penkett et al. 2006). To decrease the likelihood of false-positive or false-negative scoring events that could affect our conservation analysis, all of the 39 Drosophila homolog genes used in this analysis were rescreened during the validation round, regardless of their initial score in the primary screen. In total, we identified 18 factors that possessed common export function between the two organisms (Fig. 2A, overlap). The observation that many yeast mRNA export factor homologs are not required in the Drosophila pathway could indicate an increase in the redundancy of the factors' export functions in higher eukaryotes (Gatfield and Izaurralde 2002; Longman et al. 2003). Interestingly, the degree of amino acid sequence conservation between factors required in both organisms is significantly higher than that between factors required in yeast but not in Drosophila cells (Fig. 2B, $P=0.0344$ ). Conservation at the level of amino acid sequence suggests a critical role for these proteins in mRNA export among eukaryotes. Not surprisingly, the Drosophila factors required in both organisms are mostly composed of nuclear transport $(33 \%)$ and mRNA processing (39\%) factors (Fig. 2A). The 54 additional Drosophila export factors identified in our screen (Fig. 2A, light gray) are distributed among the RNA processing $(20 \%)$, ribosomal $(21 \%)$, cell cycle control $(13 \%)$, and unknown $(23 \%)$ categories. This analysis implies that nuclear transport factors and some mRNA processing machinery comprise a conserved core of the mRNA export pathway, while components with other facilitative or regulatory roles may have evolved to accommodate the more complex needs of metazoan cells.

\section{Spliced and unspliced transcripts have different export requirements}

Proper splicing of intron-containing transcripts is particularly important for efficient mRNA export in meta- 
A

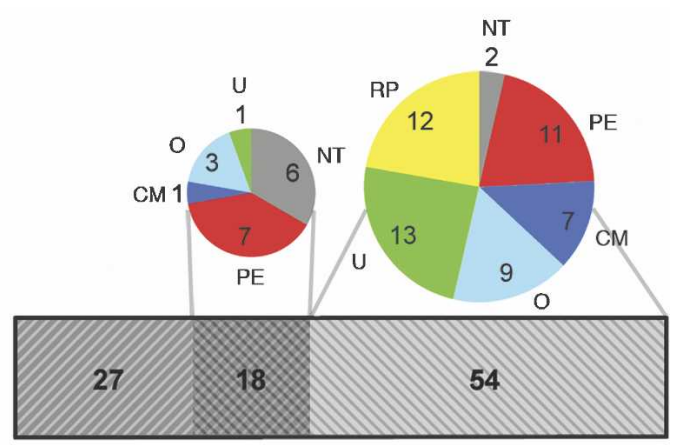

B

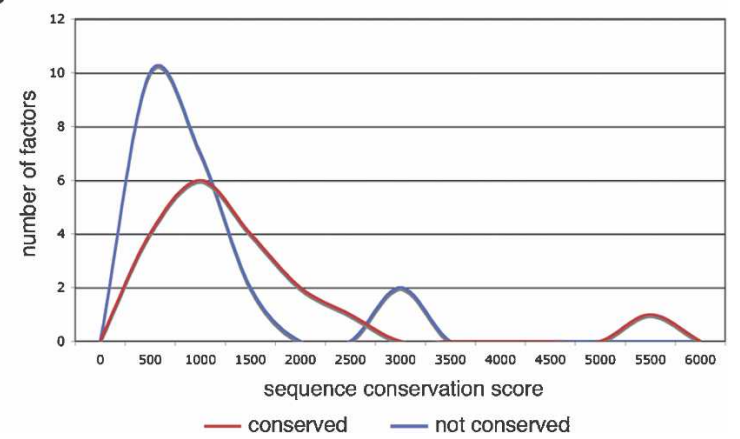

Figure 2. mRNA export pathways have evolutionarily diverged between $S$. cerevisiae and Drosophila. (A) Shaded bar represents the degree of overlap in mRNA export function between 45 unique factors required for poly- $\left(\mathrm{A}^{+}\right)$mRNA export in $S$. cerevisiae (dark gray, left) and 72 unique factors required in Drosophila identified in this screen (light gray, right). Eighteen of these factors had homologs required for mRNA export in both organisms (overlap). Gene ontology categories of these two groups of Drosophila factors are depicted and labeled as in Figure 1B. (B) Entire ORF amino acid sequences of yeast mRNA export factors were analyzed for sequence similarity and identity with those of their corresponding fly homologs. Line graph illustrates sequence conservation score frequency for homologs whose mRNA export function is conserved (red) and not conserved (blue) in Drosophila.

zoan cells (Luo and Reed 1999; Zhou et al. 2000), and export machinery is recruited directly to sites of transcription and splicing (Lei et al. 2001; Lei and Silver 2002; Custodio et al. 2004; Moore et al. 2006). To assess the effect of intron status on mRNA export requirements, we classified our 72 general factors based on their importance in the export of endogenous intron-containing and intronless messages. Using RNA FISH, we evaluated the localization of the endogenous heat-shock-inducible HSP70 (heat-shock protein 70) mRNA, an intronless HSP gene, and HSP83 mRNA, an introncontaining HSP gene, in heat-shocked cells depleted of validated export factors. We found that depletion of seven of the 72 mRNA export factors blocked export of both endogenous HSP70 and HSP83 mRNA (Fig. 3A, panels a,b,e,f; Table 1) whereas depletion of an additional 11 factors blocked export of only HSP83 mRNA (Fig. 3A, panels c,g). Importantly, of our 72 general export factors, those necessary for HSP70 mRNA export were also necessary for HSP83 mRNA export (Table 1). These components include NXF1, p15, and UAP56, which are known to be required both for bulk and HSP-specific mRNA export in Drosophila (Gatfield et al. 2001; Herold et al. 2001). Our data identify core export factors required by all transcripts even under heat stress conditions. Most factors required uniquely by HSP83 mRNAs belong to the mRNA processing and export subclass (Fig. 3B).

We further interrogated a subset of factors required for HSP83 mRNA export, and confirmed the function of some of these factors in the splicing of the HSP83 intron. Real-time PCR was used to measure the relative abundance of unspliced versus spliced HSP83 mRNA in knockdown cells after heat shock (Fig. 3C). Factors analyzed that were required for both HSP70 and HSP83 mRNA export (NXF1, UAP56, CG6694, and CG7351hereafter referred to as dmPCID2, for Drosophila melanogaster PCID2, based on its identity with its human homolog) demonstrated only a moderate or no effect on the relative levels of unspliced transcript. In contrast, factors that showed the greatest defect in HSP83 splicing (>3.9-fold) upon depletion by dsRNA were among those selectively required for HSP83 mRNA export (CG2807, CG5931, CG2685, Pitslre, and Bx42). CG5931 and homologs of CG2807, CG2685, PITSLRE, and Bx42 have been demonstrated to affect splicing in Drosophila or other organisms (Stevens et al. 2002; Hu et al. 2003; Figueroa and Hayman 2004; Park et al. 2004). Thus, we established a role for all five of these factors in the splicing and subsequent export of the HSP83 transcript.

\section{Previously uncharacterized export factors interact with the core export machinery}

To define further the relevance of factors with previously uncharacterized export function to the export pathway, we chose two independent modes of investigation. First, we investigated the subcellular localization of the new factors, and looked for physical interaction of new factors with the core component, NXF1. Since antibodies to each endogenous factor were not available, these experiments required the use of exogenously expressed versions of the proteins. Second, we assessed the transcriptional feedback from new factors to core components in the export pathway.

We transiently expressed V5-tagged versions of seven of these uncharacterized export factors in $\mathrm{S}_{2} \mathrm{R}^{+}$cells and assessed their subcellular localization by immunofluorescence microscopy. Six of these factors localized to the nucleus while one, dmPCID2, localized to the cytoplasm (Fig. 4A). We next performed coimmunoprecipitation assays with the seven V5-tagged constructs and GFPNXF1 (Fig. 4B). As anticipated, GFP-NXF1 coimmunoprecipitated with V5-p15 (Fig. 4B). Significant interactions were also seen with V5-tagged dmPCID2, CG2063, CG6694, and CG2685. While V5-tagged constructs 1(1)10Bb, CG14701, and CG31126 were efficiently immunoprecipitated by the V5 antibody, they did not show 
A

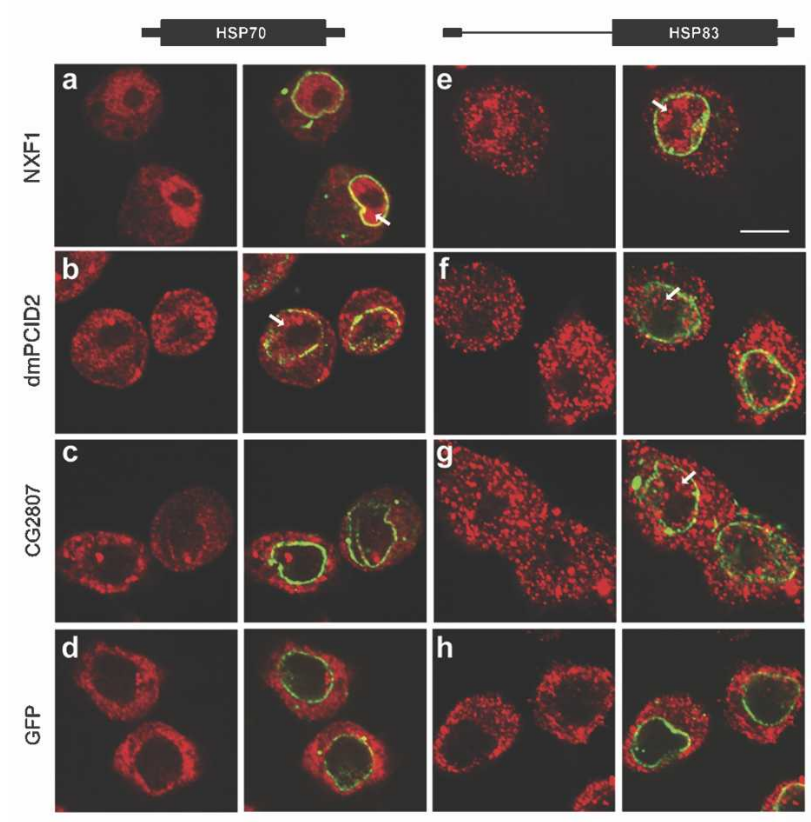

B
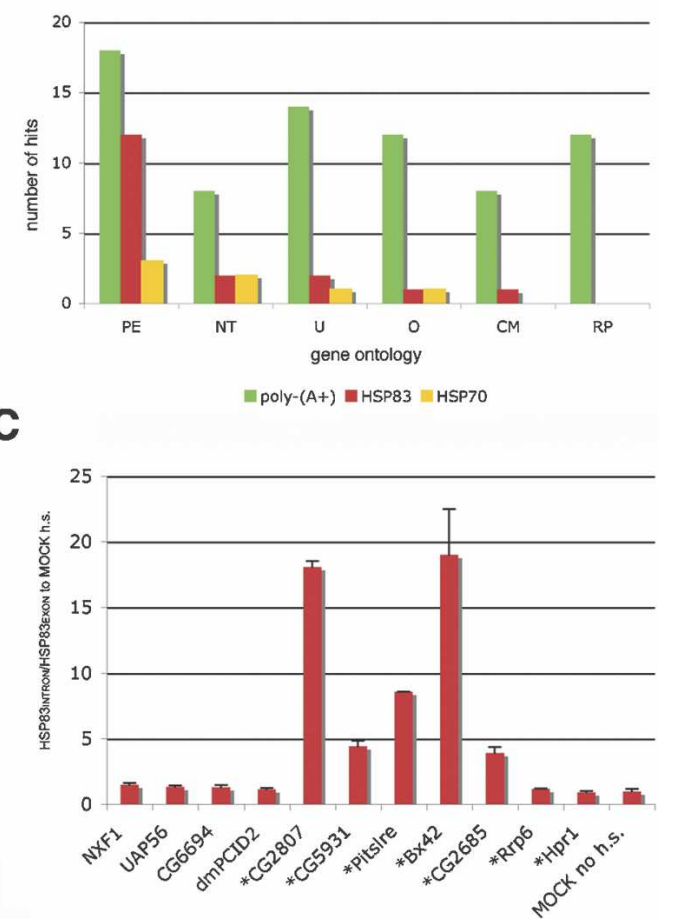

Figure 3. Export of HSP83 (intron-containing) and HSP70 (intronless) mRNAs require different sets of factors, highlighting specificity in mRNA processing requirements. (A) Localization of endogenous HSP70 (panels $a-d$ ) and HSP83 (panels $e-h$ ) mRNAs was determined by FISH. Nuclear accumulation is highlighted with arrows. Cells shown were treated with dsRNAs targeting genes listed for $4 \mathrm{~d}$. After heat shock, fixation, and hybridization with probes against endogenous HSP70 or HSP83 mRNAs (red), localization was determined by overlaying images with WGA (green). Bar, $4 \mu \mathrm{m}$. (B) Bar graph illustrates the number of factors from each gene ontology category (as labeled in Fig. 1B) that were obtained from the primary [poly-( $\left.\mathrm{A}^{+}\right)$, green] and secondary (HSP83, red; HSP70, yellow) screens. (C) Real-time PCR analysis of HSP83 mRNA species in cells treated with dsRNAs (shown at bottom) measures levels of unspliced HSP83 transcript relative to spliced HSP83 transcript of a representative biological replicate. Factors selectively required for HSP83 export are marked with an asterisk.

an interaction with GFP-NXF1. None of the V5-tagged constructs tested showed any association with GFP alone (data not shown). We therefore demonstrated that four of our uncharacterized mRNA export factors associate, either directly or indirectly, with NXF1.

To assess the effects that these seven novel export factors may have on the expression levels of the core export machinery, we monitored the transcriptional response of cells depleted of NXF1, p15, and each of the novel factors. Previous work has illustrated that a compensatory up-regulation of the expression of NXF1 and p15 mRNA occurs in response to their own depletion, potentially indicating the existence of a transcriptional feedback loop within the export pathway network (Herold et al. 2003). The levels of NXF1, p15, UAP56, and a ribosomal protein (RP49) mRNA were assessed by real-time PCR in cells that were depleted of export factors and compared with those of cells treated with GFP dsRNA (Fig. 4C). As documented previously, depletion of either NXF1 or p15 results in a reciprocal up-regulation of mRNA levels of the other factor (Herold et al. 2003). Additionally we found that both NXF1 and p15 mRNAs were up-regulated upon depletion of the novel factor, CG6694. We also observed a specific increase in p15 mRNA in cells depleted of 1(1)10Bb. Thus, at least two of our novel export factors influence the levels of mRNA encoding core export components, likely representative of the cell's attempt to compensate for an mRNA export blockage.

Furthermore, mRNA levels of RP49, an abundant transcript indicative of total RNA levels, were decreased in NXF1-, CG6694-, 1(1)10Bb-, and CG14701-depleted cells. This reduction could be indicative of a destabilization of this transcript in response to defective processing or export of RP49 mRNA (Herold et al. 2003). It has been shown that aberrantly transcribed or processed transcripts are often targeted by the nuclear exosome for degradation in order to prevent the cell from accumulating faulty transcripts (Libri et al. 2001; Zenklusen et al. 2002; Davis and Ares 2006).

dmPCID2 is an export factor that associates with translationally active complexes

Our subcellular localization analysis indicated that dmPCID2 resides predominantly within the cytoplasm 
Table 1. Results of HSP7O and HSP83 screens

\begin{tabular}{lccc}
\hline Gene & HSP83 & HSP70 & Gene ontology $^{\text {a }}$ \\
\hline UAP56 & ++ & ++ & PE \\
Kary33 & ++ & ++ & NT \\
Nup153 & ++ & ++ & NT \\
p15 & ++ & ++ & PE \\
NXF1 & ++ & ++ & PE \\
CG7351/dmPCID2 & ++ & + & O \\
CG6694 & ++ & + & U \\
CG18591 & ++ & - & PE \\
CG2807 & ++ & - & PE \\
CG5931 & ++ & - & PE \\
Bx42 & ++ & - & PE \\
Hpr1 & + & - & PE \\
Rrp6 & + & - & PE \\
CG2685 & + & - & U \\
noi & + & - & PE \\
Pabp2 & + & - & PE \\
Pitslre & + & - & CM \\
Ssrp & + & - & PE \\
\hline
\end{tabular}

${ }^{a}$ Gene ontology categories: (PE) mRNA processing and export; $(\mathrm{CM})$ cell cycle control and mitosis; $(\mathrm{NT})$ nuclear transport; $(\mathrm{O})$ other; (U) unknown.

$(++)$ Nuclear accumulation of mRNA $(>50 \%$ penetrance of phenotype); (+) nuclear accumulation of $\mathrm{mRNA} \mid<50 \%$ penetrance of phenotype); (-) no nuclear accumulation of mRNA.

(Fig. 4A). Interestingly, its yeast sequence homolog, Thplp, is a factor thought to play a role in coupling transcription to export and localizes to the nuclear pore (Fischer et al. 2002; Gallardo et al. 2003). dmPCID2, Thplp, and the uncharacterized human (hs)PCID2 each contain a PCI domain (Fig. 5A); a structurally defined, $\alpha$-helical, protein-protein interaction domain characteristic of eIF3 translation initiation factors; the COP9 signalosome; and the proteasome lid complex (Hofmann and Bucher 1998). While dmPCID2 contains a domain similar to these cytoplasmic complexes, it also affects the export of bulk mRNA and specific HSP transcripts from the nucleus. To test whether dmPCID2 can shuttle into the nucleus, we exposed cells transfected with V5dmPCID2 to the nuclear export inhibitor Leptomycin B (LMB). Upon LMB treatment, transfected cells accumulated dmPCID2 within the nucleus (Fig. 5C [red, top panels], D) while the localization of the cytoplasmic RNAbinding protein FMR1 (Fig. 5C, green) remained static, indicating that dmPCID2 actively shuttles between the nucleus and the cytoplasm by a Crm1-dependent mechanism. Intriguingly, deletion of the PCI domain (V5- $\Delta \mathrm{PCI}$ ) (Fig. 5C [red, lower panels], D) increased the shuttling activity of dmPCID2. Blinded counting of transfected cells revealed that shuttling of dmPCID2 was significantly enhanced upon deletion of the PCI domain (Fig. 5D).

To determine whether the PCI domain was important for the association of NXF1 and dmPCID2, we performed coimmunoprecipitation experiments with V5-tagged dmPCID2 or V5- $\triangle$ PCI and GFP-NXF1 (Fig. 5B). Deletion of the PCI domain did not affect the interaction of V5dmPCID2 with GFP-NXF1. Further, neither interaction was affected by RNase treatment, indicating that the interaction between dmPCID2 and NXF1 is not RNA-dependent. These results suggest that dmPCID2 and NXF1 participate in a protein-dependent interaction, and that the potential role of dmPCID2 in mRNA export does not depend on the function of its PCI domain.

Given the homology of the PCI domain of dmPCID2 with that of the translation initiation factor eIF3m (Fig. $5 \mathrm{~A})$, we inquired whether dmPCID2 is associated with translationally active complexes. We performed sucrose density gradient fractionation on $\mathrm{S} \mathrm{R}^{+}$cells transiently transfected with either V5-dmPCID2 or V5- $\Delta$ PCI (Fig. 6). Lysates from transfected cells were separated on sucrose density gradients either not containing or containing EDTA, a treatment that disrupts interactions between the large (60S) and small (40S) ribosomal subunits. In control samples, a significant proportion of the V5-dmPCID2 protein cosedimented with fractions that contain fully assembled ribosomes (80S) and polysomes, as confirmed by detection of the ribosomal protein P0. Importantly, the proportion of dmPCID2 associating with polysomes is significantly decreased upon deletion of the PCI domain. Monitoring of fractions by UV fluorescence demonstrates that EDTA treatment efficiently disrupted the ribosomal subunits and disassembled polysomes. This perturbance caused ribosomal protein P0 as well as dmPCID2 to shift to the less dense fractions of the gradient, indicating that the presence of dmPCID2 in heavier fractions is dependent on ribosomal integrity. This analysis indicates that at least part of the cellular pool of dmPCID2 is normally associated with translationally active polysomes, and that this association is greatly mediated by the PCI domain.

\section{Discussion}

mRNA processing events are linked to each other through an elaborate system of coupling, spanning from transcription to translation. Here we presented the first whole-genome screen for factors required for the nuclear export of poly- $\left(\mathrm{A}^{+}\right)$mRNA in a metazoan system. In addition, we examined how mRNA export pathways may have evolved between yeast and metazoan cells. Further, we investigated several factors identified in our screen to place them within the mRNA export pathway with respect to their potential connections to transcription, splicing, and translation.

\section{An increase in genome complexity results in an increase in export network complexity}

mRNA nuclear export is an essential process in all eukaryotes. However, prior to this study, the degree of conservation between mRNA export pathways of yeast and a higher eukaryotic organism had not been determined on a genome-wide scale. Here we present evidence that core components of the mRNA export pathway are required for the export process by both organisms. Furthermore, these particular components display a greater de- 
Farny et al.

A
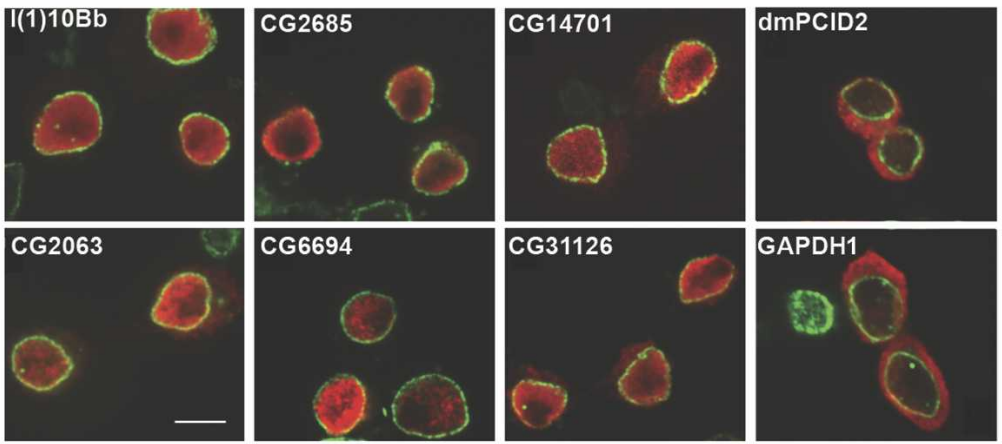

B

Figure 4. Select novel export factors physically interact with NXF1 or affect the mRNA expression levels of core export factors. (A) Plasmids encoding seven V5-tagged uncharacterized mRNA export factors or GAPDH1 were transfected into $\mathrm{S} \mathrm{R}^{+}$cells, then fixed and stained with anti-V5 antibody (red) and WGA (green). Bar, $4 \mu \mathrm{m}$. (B) V5-tagged export factors depicted in $A$ were cotransfected with GFP-NXF1 and coimmunoprecipitated using mouse-anti-V5 antibody. Asterisk indicates V5-CG6694, which has low expression in these cells. $(C)$ Real-time PCR analysis of NXF1 (red), p15 (yellow), UAP56 (green), and RP49 (light gray) mRNA levels in response to depletion of select novel export factors of a representative biological replicate. Efficient knockdown was confirmed by using primer sets targeting each export factor's mRNA (dark gray).

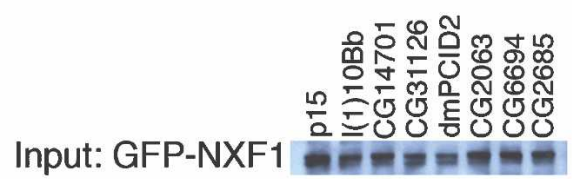

Input: GFP-NXF1 aㅡㄹ

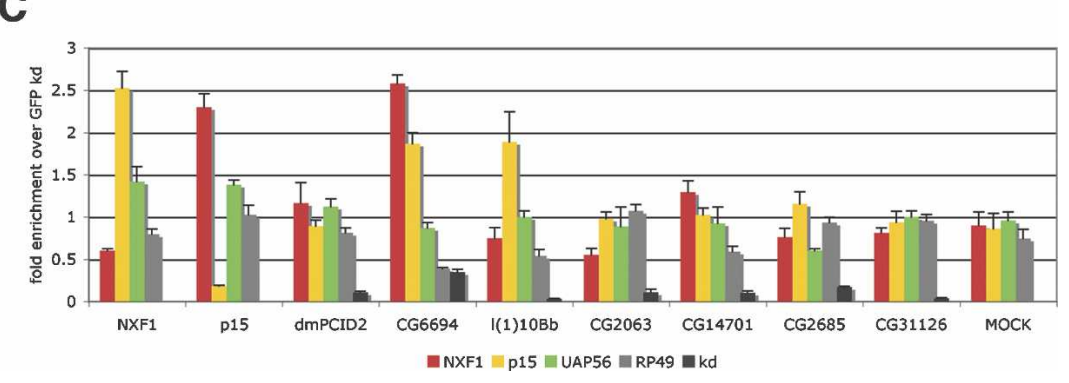

gree of sequence conservation between them than those that are not conserved functionally between the pathways. We believe this sequence conservation indicates the evolutionary importance of the core mRNA export factors. Importantly, in addition to conservation between export pathways of both organisms, there are significant differences in the export requirements of these systems. It is possible that some of the differences we identified in the export pathways of yeast and Drosophila are due to the existence of functional homologs in each system that are not related at the sequence level. However, we believe the additional components required by Drosophila may be representative of other pathways that have evolved to take a role in the export of mRNA transcripts generated by more complex processing events characteristic of a metazoan cell.

The comparative analysis of export factors between $S$. cerevisiae and Drosophila is partially based on the negative results for certain factors in our export assay. Due to the lack of available antibodies, we were unable to monitor the efficiency of depletion of these negative factors. However, negative factors important to our evolutionary analysis were screened for export defects using at least two separate, nonoverlapping dsRNAs per factor in order to reduce the possibility of false-negative results. In addition, we spot-checked the knockdown efficiency at the mRNA level of a small panel of negative factors using quantitative real-time PCR and found that the dsRNAmediated depletion of these factors was comparable with that of our positive control NXF1 (data not shown).

\section{$m R N A$ export requirements reflect $m R N A$} processing requirements

The export pathways of all mRNAs are not identical. Studies in this laboratory (Brodsky and Silver 2000; Hieronymus and Silver 2003; Yu et al. 2004; Moore et al. 2006) and others (Rehwinkel et al. 2004; Kim Guisbert et 
A
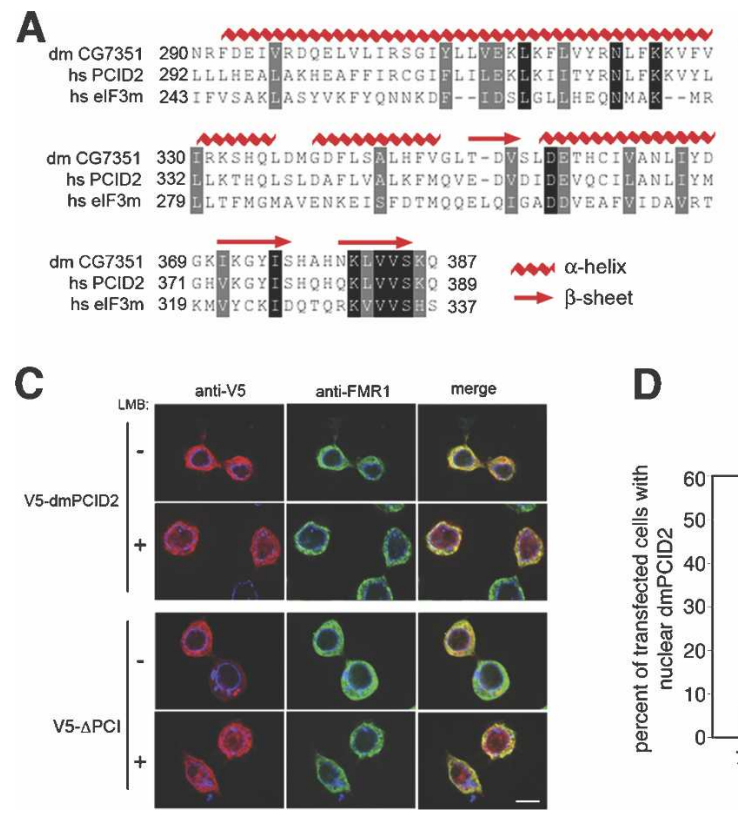

B
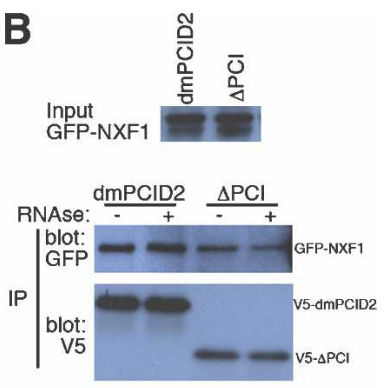

D

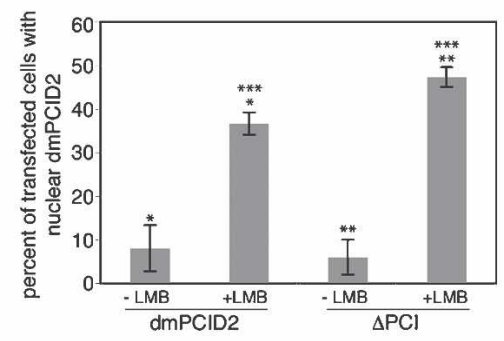

Figure 5. The mRNA export factor dmPCID2 shuttles between the nucleus and the cytoplasm. (A) Alignment of the PCI domains of Drosophila dmPCID2, human hsPCID2, and human eIF3m with predicted secondary structure shows the high proportion of $\alpha$-helical regions, characteristic of this domain. Similar (gray) and identical (black) amino acids in this alignment are indicated. $(B)$ Coimmunoprecipitation of V5-dmPCID2 and V5$\triangle$ PCI with GFP-NXF1. (C) Nucleocytoplasmic shuttling of dmPCID2 and $\triangle$ PCI. Cells were transfected with V5-dmPCID2 or V5- $\triangle \mathrm{PCI}$, treated with LMB (10 nM, 3 $\mathrm{h})$, then fixed and costained for V5 (red), FMR1 (green), and WGA (blue). Bar, $4 \mu \mathrm{m}$. (D) Quantification of nucleocytoplasmic shuttling of dmPCID2 and $\triangle$ PCI. $P$-values:

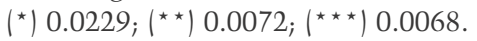

al. 2005) have illustrated that there is specificity in the factors employed by each transcript for its processing and subsequent export. Our results show that unspliced HSP70 transcripts require fewer export factors than do spliced HSP83 transcripts, and that some of the additional factors required for HSP83 mRNA export are also important for its efficient splicing. However, although some processing steps appear to be transcript-specific, key factors late in the export process appear to be invariant in their requirement for message export. Indeed, the populations of mRNAs selectively retained in the nucleus of Drosophila cells upon knockdown of NXF1, p15, or UAP56 are markedly similar (Herold et al. 2003). Here we show that although HSP70 mRNAs required fewer of the factors tested for export than did HSP83 mRNAs, the subset of general mRNA export factors required by HSP70 were also required by HSP83. This result suggests that the factors common to HSP70 and HSP83 export comprise a minimum core of required factors for export of all transcripts even under conditions of cellular stress, and as such are not likely to be messagespecific (Fig. 7). The degree of specificity of each export and processing factor for transcripts remains to be completely understood and is likely to contribute to the exquisite control a cell exerts over its expression program.

Notably, these experiments interrogated only the 72 general mRNA export factors derived from our primary screen for their importance in HSP mRNA export. It is probable that additional factors outside of these 72 components are required for HSP transcript export and that some of these additional factors would be individually or commonly required by HSP83 and HSP70 mRNAs. We chose the HSP mRNAs for this assay because they were both endogenous and robustly inducible, making them more amenable to high-throughput FISH techniques and allowing us to be confident that our signal was specific.

\section{Novel export factors influence core export machinery}

Genome-wide RNAi screens expose both direct and indirect players in any process being examined. Here we showed that at least some of our novel factors have direct effects on mRNA export in two ways. First,

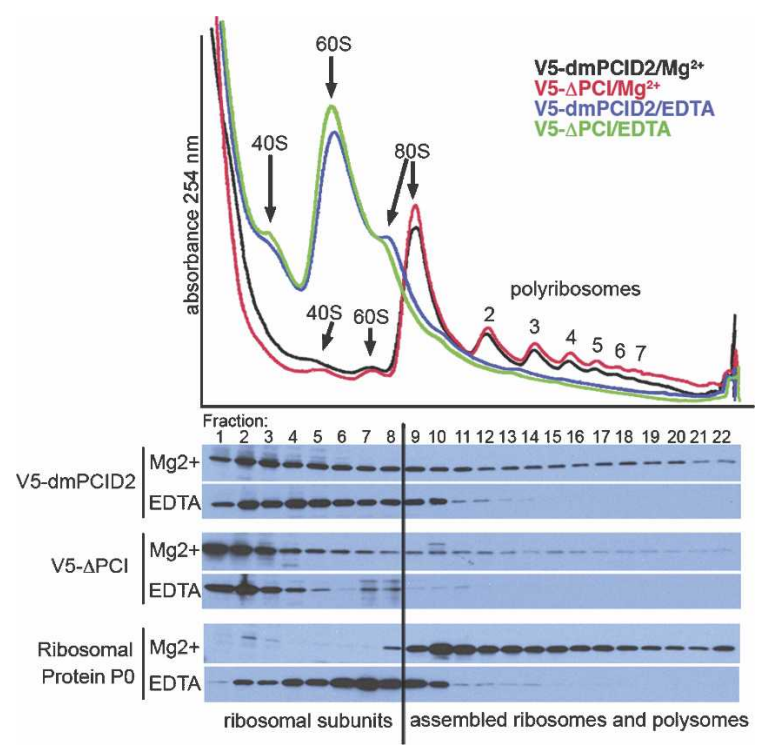

Figure 6. $d m P C I D 2$ is associated with polysomes. Cells transfected with V5-dmPCID2 or V5- $\triangle \mathrm{PCI}$ were lysed and layered on $10 \%-50 \%$ sucrose gradients. (Top) After centrifugation, fractions were collected and UV profiles were monitored at $254 \mathrm{~nm}$ under control (black and red) or polysome-disrupting (EDTA, blue and green) conditions. (Bottom) Fractions were analyzed by Western blot using anti-V5 or anti-ribosomal protein P0 antibodies. 


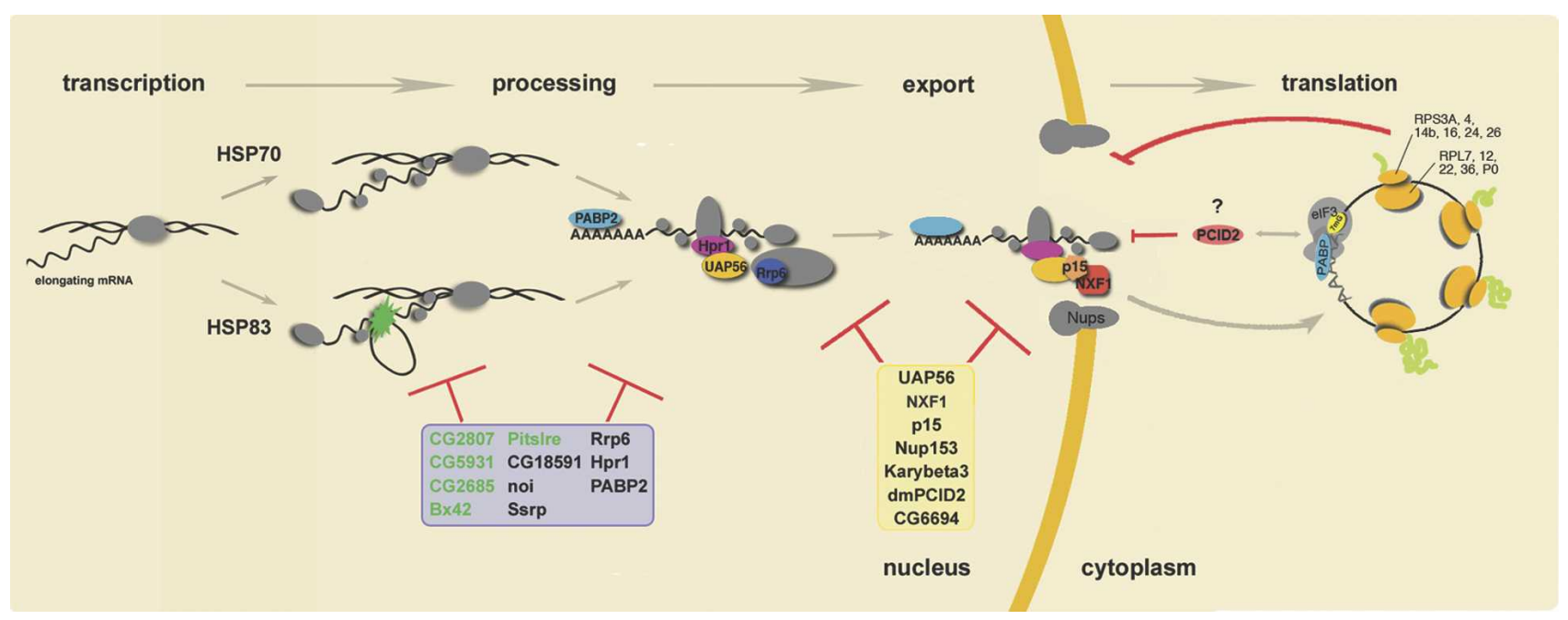

Figure 7. A model of mRNA export in Drosophila. Many RNA-binding proteins interact with messages during their processing and export from the nucleus. Upon heat shock, a subset of factors is required for the export of both intronless (HSP70, top) and introncontaining (HSP83, bottom) transcripts. These core factors likely act during general processing steps or message recruitment and nuclear exit (yellow box). Since HSP83 messages must be properly spliced prior to export, additional factors are required for this particular processing step and subsequent export (blue box). Factors demonstrated to be required for proper splicing of the HSP83 message in Figure 3C are shown in green. After export, mRNAs are circularized and bound by translation initiation factors (eIFs) and a polysome is formed. Certain ribosomal subunits identified in this screen may be involved in a feedback mechanism that regulates mRNA export. Likewise, dmPCID2 may be associating with the eIF3 complex through its PCI domain and could mediate the transition of an exported mRNP into a polysome.

CG6694, CG2063, CG2685, and dmPCID2 were found to interact with NXF1 by coimmunoprecipitation assays (Fig. 4B). Second, CG6694 and 1(1)10Bb were found to have a compensatory transcriptional up-regulation of core export factors upon their dsRNA-mediated depletion, as determined by quantitative real-time PCR analysis (Fig. 4C). CG6694 was the only factor tested to show both a transcriptional effect and a physical interaction with NXF1. Interestingly, CG6694 possesses homology with a member of the cleavage and polyadenylation specificity factor (CPSF) complex that is required for proper 3'-processing of mRNAs. We speculate that this factor may play a role in the recruitment of NXF1 to cleaved and polyadenylated transcripts. While the full elucidation of the roles of these factors in mRNA export will require future study, the assays described demonstrate that at least some of our novel factors are direct participants in the mRNA export pathway in Drosophila.

\section{Translation and cell cycle regulation may be linked to mRNA export}

In addition to identifying many novel factors that affect mRNA export, our results illuminate connections between export and both translation and cell cycle regulation. dmPCID2 was a previously uncharacterized fly protein that we found to specifically interact with NXF1 in an RNA-independent manner. Additionally, we showed that dmPCID2 shuttles in and out of the nucleus by a Crm1-dependent mechanism, and that the NXF1 inter- action and shuttling properties of dmPCID2 are not due to the presence of its PCI domain. However, association of dmPCID2 with polysomes is strongly dependant on the PCI domain. We propose that dmPCID2 may act as a bridge between mRNA export and translation by mediating an interaction between the exported mRNP bound to NXF1 and the translation machinery, perhaps via interactions with the PCI-containing translation initiation complex eIF3 (Fig. 7).

Our screen results identified eight export factors that were already implicated in regulation of the cell cycle. The cyclin-dependent kinase CDK11 (Drosophila PITSLRE) plays a role in transcription and splicing through phosphorylation of the SR splicing factor 9G8 in human cells (Hu et al. 2003), and phosphorylation-dependent interactions between NXF1 and SR adaptor proteins have been documented (Huang et al. 2004). Regulating interactions of NXF1 with the mRNP via cell cycle-dependent phosphorylation events is an intriguing mechanism for linking cell growth and mRNA export.

In summary, we present the results of the first genome-wide metazoan mRNA export screen. Our results provide important new groundwork for the study of the essential process of nuclear mRNA export in higher eukaryotes.

\section{Materials and methods}

Cell lines and constructs

Drosophila S2R ${ }^{+}$cells were obtained from N. Perrimon (Harvard Medical School, Boston, MA) and were maintained in 
Schneider's Drosophila Medium (Invitrogen) containing 10\% fetal bovine serum and penicillin/streptomycin solution. Full coding regions of genes used for expression studies were cloned by RT-PCR from total RNA isolated from $\mathrm{S}_{2} \mathrm{R}^{+}$cells, and were inserted into pAc5.1-V5/His (Invitrogen) or pAc5.1 containing an $\mathrm{N}$-terminal GFP.

\section{Whole-genome RNAi screen}

The full genome dsRNA library was obtained from the Drosophila RNAi Screening Center (DRSC) at Harvard Medical School (http://www.flyrnai.org). Approximately 21,300 dsRNAs were synthesized and arrayed in duplicate in 63 384-well black, clear-bottomed plates by the DRSC. S2R ${ }^{+}$cells were scrapeharvested, counted, and resuspended in serum-free medium. Cells $\left(3 \times 10^{4}\right)$ were added to each well containing $0.25 \mu \mathrm{g}$ of dsRNA, incubated for $30 \mathrm{~min}$, then supplemented with complete growth media and incubated for $4 \mathrm{~d}$ at $25^{\circ} \mathrm{C}$. FISH of screen plates was adapted from described protocols (Herold et al. 2001; Kedersha et al. 2002) as follows: The plates were fixed in $4 \%$ paraformaldehyde in PBS (4\% PF/PBS) for $10 \mathrm{~min}$, post-fixed in methanol for $10 \mathrm{~min}$, and rehydrated in $70 \%$ ethanol for $10 \mathrm{~min}$. The plates were then washed in $1 \mathrm{M}$ Tris $(\mathrm{pH} 8)$ for $5 \mathrm{~min}$, then hybridized for $1 \mathrm{~h}$ at $37^{\circ}$ with a Cy3-Oligo-d $T_{(30)}$ probe (Integrated DNA Technologies) at $1 \mu \mathrm{g} / \mathrm{mL}$ in hybridization buffer (25\% formamide, $10 \%$ dextran sulfate, $0.005 \%$ BSA, $1 \mathrm{mg} / \mathrm{mL}$ yeast tRNA in $2 \times$ SSC). The plates were washed twice in $2 \times$ SSC at $25^{\circ} \mathrm{C}$ and stained with Hoechst 33325 dye (Sigma) at $0.5 \mu \mathrm{g} /$ $\mathrm{mL}$ in $2 \times$ SSC. Plates were imaged using the ImageXpress Micro (Molecular Devices) at the Institute for Chemistry and Cell Biology (ICCB) at Harvard Medical School, and the images were collected using MetaXpress software (Molecular Devices). Images were inspected visually for an mRNA export defect phenotype. The screen was performed in duplicate. For validation of the primary assay, a set of separate, nonoverlapping dsRNAs, all having no predicted off-target effects (based on 19-base-pair identity), was employed to rescreen candidate genes from the primary screen. dsRNAs were synthesized from T7-ended DNA templates obtained from the DRSC, using the MEGAscript T7 Transcription kit (Ambion) and purified using the RNeasy kit (Qiagen) per the manufacturers' protocols. The mRNA export assay described above was then repeated at three time points: 72 h, $96 \mathrm{~h}$, and $144 \mathrm{~h}$.

\section{Secondary screening of HSP70 and HSP83 mRNA export}

Validated dsRNAs from the primary screen were examined for export defects of specific transcripts using probes against endogenous HSP70 and HSP83. To visualize HSP70 mRNA, a series of three Cy3-labeled HSP70 oligonucleotide probes (Integrated DNA Technologies) were used at a final concentration of $2 \mu \mathrm{g} /$ $\mathrm{mL}$ each in hybridization buffer. Plates were heat-shocked for 1 $\mathrm{h}$ at $37^{\circ} \mathrm{C}$, then fixed and hybridized as described for the primary screen. To visualize HSP83 mRNA (Herold et al. 2001), a digoxygenin-labeled dsDNA probe was produced as described (Gilks et al. 2004), denatured for $7 \mathrm{~min}$ at $95^{\circ} \mathrm{C}$, and then diluted 1:100 in hybridization buffer. Samples were denatured for 10 min at $65^{\circ} \mathrm{C}$, then hybridized for $16 \mathrm{~h}$ at $45^{\circ} \mathrm{C}$. The samples were then washed as described, except that the washes were performed at $45^{\circ} \mathrm{C}$, then stained with sheep-anti-digoxygenin (Roche) at 1:200, then donkey-anti-sheep Cy3 secondary antibody at 1:2000, plus Hoechst and Alexa-488-wheat germ agglutinin (WGA) as described.

\section{Immunofluorescence staining and microscopy}

S2 $\mathrm{R}^{+}$cells were plated on glass coverslips in a 24-well plate and transfected using Effectene Transfection Reagent (Qiagen) per the manufacturer's protocols. After $24 \mathrm{~h}$, the cells were fixed first in $0.5 \%$ Triton X-100 + 2\% PF/PBS for $5 \mathrm{~min}$, and then $4 \%$ $\mathrm{PF} / \mathrm{PBS}$ for $10 \mathrm{~min}$, then rinsed with $\mathrm{PBS}$ and blocked in $5 \%$ normal donkey serum in PBS (NDS/PBS). All antibodies were diluted in NDS/PBS as follows: V5 mAb (Sigma), 1:1000; donkey-anti-mouse Cy3 (Jackson Immunoresearch), 1:2000; Hoechst (Sigma), 1:1000; Alexa-488-WGA (Invitrogen), 1:1000. Incubations were performed for $1 \mathrm{~h}$ at room temperature, followed by three 5-min washes in PBS, then mounted on slides for microscopy. Images were taken on a Nikon TE2000 inverted fluorescence microscope with $3 \mathrm{~W}$ laser spinning disc confocal using a 100× Plan-Apo lens, acquired using MetaMorph software (Molecular Devices), and compiled for figures using Adobe Photoshop CS software. Leptomycin B (Sigma) was used at 10 $\mathrm{nM}$ for $3 \mathrm{~h}$ before fixation and staining as described.

\section{Immunoprecipitation experiments}

V5-tagged constructs were transiently cotransfected into S2R ${ }^{+}$ cells with either GFP-NXF1 or GFP. At $20 \mathrm{~h}$, cells were lysed in immunoprecipitation (IP) buffer (20 mM Tris at pH 7.5, $200 \mathrm{mM}$ $\mathrm{NaCl}, 0.5 \mathrm{mM}$ EDTA $10 \%$ glycerol, $0.5 \%$ NP-40, plus protease inhibitors [Roche]). Input lysates were precleared with protein A sepharose beads (Amersham), then incubated with V5-agarose (Sigma) beads overnight at $4^{\circ} \mathrm{C}$. V5-agarose beads were then washed three times in room temperature IP buffer and eluted in SDS Lammeli buffer by boiling. Where shown, RNase A and T cocktail (Ambion) was added to lysates for $30 \mathrm{~min}$ at $25^{\circ} \mathrm{C}$ before addition of antibody.

\section{Sequence alignment}

Amino acid sequence conservation between $S$. cerevisiae and $D$. melanogaster homologs (Fig. 2; Supplemental Table S2) was determined using the pairwise alignment tool at http://www.ebi. ac.uk/emboss/align with the following parameters: NeedlemanWunsch global alignment algorithm (Needleman and Wunsch 1970), Blosum62 substitution matrix, gap penalty 5.0, and gap extension penalty 0.5 (Pillai et al. 2005). Alignments for Figure 5 were constructed using the Multiple Sequence Alignment (Huang 1994) tool at http://genome.cs.mtu.edu/map.html, and identity/similarty shading was performed using the Multiple Align Show (Stothard 2000) tool at http://bioinformatics.org/ sms/index.html. Structural predictions were obtained using the SSpro8 secondary structure prediction (Pollastri et al. 2002) tool at http://www.ics.uci.edu/ baldig/scratch.

\section{Real-time PCR}

Knockdowns were performed in biological duplicate for $4 \mathrm{~d}$ as described previously except $2 \times 10^{6} \mathrm{~S}^{2} \mathrm{R}^{+}$cells were seeded in a six-well plate format and $1 \mathrm{~mL}$ of serum-free media, $25 \mu \mathrm{g}$ of dsRNA, and $3 \mathrm{~mL}$ of complete media were used. Cells were heat-shocked and scrape-harvested, and total RNA was isolated using the RNeasy kit (Qiagen) as per the manufacturer's protocols. Samples were DNase-treated (Ambion) and 2.75-3 $\mu \mathrm{g}$ of total RNA were used in cDNA synthesis reactions containing Oligo dT and SuperScript III (Invitrogen). cDNAs were diluted appropriately and used as input in real-time PCR reactions containing iQ SYBR Green (Bio-Rad) and $50 \mathrm{nM}$ oligonucleotide primers interrogating either Drosophila HSP83 intronic or exonic sequence. An intergenic primer set was additionally analyzed to ensure that no genomic sequence was present in each cDNA preparation. A ratio of the levels of intron-containing transcript to exon-containing transcript was calculated for each sample and then normalized to that of a mock-treated sample 
using the $\Delta \Delta \mathrm{C}_{\mathrm{t}}$ method (Livak and Schmittgen 2001). Similar techniques were employed for expression analysis, except that cells were not heat-shocked and random hexamers were used for cDNA preparation. A ratio of the levels of NXF1, p15, UAP56, RP49, or the depleted transcript to 18S rRNA was calculated for each sample and then normalized to that of a GFP dsRNAtreated sample as described above. All real-time PCR primers were designed using Primer Express 1.0 (Applied Biosystems) and are listed in Supplemental Table S3.

\section{Sucrose gradient fractionation}

$\mathrm{S} \mathrm{R}^{+}$cells $\left(3.0 \times 10^{7}\right)$ were transfected with V5-CG7351 as described. At $24 \mathrm{~h}$, cells were scrape-harvested and lysed in lysis buffer (25 mM HEPES at pH 6.9, $100 \mathrm{mM} \mathrm{KCl}, 10 \mu \mathrm{g} / \mathrm{mL}$ cyclohexamide, $1 \mu \mathrm{g} / \mathrm{mL}$ heparin, $0.5 \% \mathrm{NP}-40$, and $5 \mathrm{mM} \mathrm{MgCl}_{2}$ or $25 \mathrm{mM}$ EDTA as appropriate). Nuclei were pelleted, and supernatants were layered onto $10 \%-50 \%$ sucrose gradients (prepared in buffer containing $25 \mathrm{mM}$ HEPES at pH 6.9, $100 \mathrm{mM}$ $\mathrm{KCl}, 10 \mu \mathrm{g} / \mathrm{mL}$ cyclohexamide, $1 \mu \mathrm{g} / \mathrm{mL}$ heparin, and $5 \mathrm{mM}$ $\mathrm{MgCl}_{2}$ or $25 \mathrm{mM}$ EDTA). After high-speed centrifugation $(35,000 \mathrm{rpm}$ for $3 \mathrm{~h})$, gradients were eluted on a gradient fractionator (Brandel) and monitored by UV at $254 \mathrm{~nm}$. Fractions were collected, acetone-precipitated, and processed for SDSPAGE, followed by blotting with anti-V5 (Invitrogen) or anti-P0 (ImmunoVision) antibodies.

\section{Acknowledgments}

We thank N. Perrimon, B. Mathey-Prevot, N. Ramadan, and members of the DRSC for reagents and advice; S. Rudnicki, C. Shamu, and members of the ICCB for assistance with imaging; N. Kedersha for protocols, reagents, and advice on in situ hybridizaiton and sucrose gradient fractionation; E. Izzauralde and J. Rehwinkel for information on HSP83 in situ probes; and members of the Silver laboratory for discussion and critical reading of this manuscript. This work was supported by the Harvard Biological and Biomedical Sciences Program (N.G.F. and J.A.H.) and grants from the NIH (to P.A.S.). N.G.F. designed and performed the primary screen, and performed coimmunoprecipitation experiments. N.G.F and J.A.H. performed the validation screening, the HSP70 and HSP83 experiments, the cloning and expression of novel factors, and sucrose gradient fractionation. J.A.H performed all real-time PCR experiments. We all contributed to discussion of results and to writing the manuscript.

\section{References}

Aguilera, A. 2005. mRNA processing and genomic instability. Nat. Struct. Mol. Biol. 12: 737-738.

Amberg, D.C., Goldstein, A.L., and Cole, C.N. 1992. Isolation and characterization of RAT1: An essential gene of Saccharomyces cerevisiae required for the efficient nucleocytoplasmic trafficking of mRNA. Genes \& Dev. 6: 1173-1189.

Armknecht, S., Boutros, M., Kiger, A., Nybakken, K., MatheyPrevot, B., and Perrimon, N. 2005. High-throughput RNA interference screens in Drosophila tissue culture cells. Methods Enzymol. 392: 55-73.

Azad, A.K., Tani, T., Shiki, N., Tsuneyoshi, S., Urushiyama, S., and Ohshima, Y. 1997. Isolation and molecular characterization of mRNA transport mutants in Schizosaccharomyces pombe. Mol. Biol. Cell 8: 825-841.

Boutros, M., Kiger, A.A., Armknecht, S., Kerr, K., Hild, M., Koch, B., Haas, S.A., Consortium, H.F., Paro, R., and Perrimon, N. 2004. Genome-wide RNAi analysis of growth and viability in Drosophila cells. Science 303: 832-835.

Braun, I.C., Rohrbach, E., Schmitt, C., and Izaurralde, E. 1999. TAP binds to the constitutive transport element (CTE) through a novel RNA-binding motif that is sufficient to promote CTE-dependent RNA export from the nucleus. EMBO J. 18: 1953-1965.

Brodsky, A.S. and Silver, P.A. 2000. Pre-mRNA processing factors are required for nuclear export. RNA 6: 1737-1749.

Brown, J.A., Bharathi, A., Ghosh, A., Whalen, W., Fitzgerald, E., and Dhar, R. 1995. A mutation in the Schizosaccharomyces pombe rae 1 gene causes defects in poly $(\mathrm{A})^{+}$RNA export and in the cytoskeleton. J. Biol. Chem. 270: 7411-7419.

Custodio, N., Carvalho, C., Condado, I., Antoniou, M., Blencowe, B.J., and Carmo-Fonseca, M. 2004. In vivo recruitment of exon junction complex proteins to transcription sites in mammalian cell nuclei. RNA 10: 622-633.

Davis, C.A. and Ares Jr., M. 2006. Accumulation of unstable promoter-associated transcripts upon loss of the nuclear exosome subunit Rrp6p in Saccharomyces cerevisiae. Proc. Nat1. Acad. Sci. 103: 3262-3267.

Figueroa, J.D. and Hayman, M.J. 2004. The human Ski-interacting protein functionally substitutes for the yeast PRP45 gene. Biochem. Biophys. Res. Commun. 319: 1105-1109.

Fischer, T., Strasser, K., Racz, A., Rodriguez-Navarro, S., Oppizzi, M., Ihrig, P., Lechner, J., and Hurt, E. 2002. The mRNA export machinery requires the novel Sac3p-Thplp complex to dock at the nucleoplasmic entrance of the nuclear pores. EMBO J. 21: 5843-5852.

Gallardo, M., Luna, R., Erdjument-Bromage, H., Tempst, P., and Aguilera, A. 2003. Nab2p and the Thp1p-Sac3p complex functionally interact at the interface between transcription and mRNA metabolism. J. Biol. Chem. 278: 24225-24232.

Gatfield, D. and Izaurralde, E. 2002. REF1/Aly and the additional exon junction complex proteins are dispensable for nuclear mRNA export. J. Cell Biol. 159: 579-588.

Gatfield, D., Le Hir, H., Schmitt, C., Braun, I.C., Kocher, T., Wilm, M., and Izaurralde, E. 2001. The DExH/D box protein HEL/UAP56 is essential for mRNA nuclear export in Drosophila. Curr. Biol. 11: 1716-1721.

Gilks, N., Kedersha, N., Ayodele, M., Shen, L., Stoecklin, G., Dember, L.M., and Anderson, P. 2004. Stress granule assembly is mediated by prion-like aggregation of TIA-1. Mol. Biol. Cell 15: 5383-5398.

Gross, T., Siepmann, A., Sturm, D., Windgassen, M., Scarcelli, J.J., Seedorf, M., Cole, C.N., and Krebber, H. 2007. The DEAD-box RNA helicase Dbp5 functions in translation termination. Science 315: 646-649.

Guzik, B.W., Levesque, L., Prasad, S., Bor, Y.C., Black, B.E., Paschal, B.M., Rekosh, D., and Hammarskjold, M.L. 2001. NXT1 (p15) is a crucial cellular cofactor in TAP-dependent export of intron-containing RNA in mammalian cells. Mol. Cell. Biol. 21: 2545-2554.

Heath, C.V., Copeland, C.S., Amberg, D.C., Del Priore, V., Snyder, M., and Cole, C.N. 1995. Nuclear pore complex clustering and nuclear accumulation of poly $(\mathrm{A})^{+}$RNA associated with mutation of the Saccharomyces cerevisiae RAT2/ NUP120 gene. J. Cell Biol. 131: 1677-1697.

Herold, A., Klymenko, T., and Izaurralde, E. 2001. NXF1/p15 heterodimers are essential for mRNA nuclear export in Drosophila. RNA 7: 1768-1780.

Herold, A., Teixeira, L., and Izaurralde, E. 2003. Genome-wide analysis of nuclear mRNA export pathways in Drosophila. EMBO J. 22: 2472-2483.

Hieronymus, H. and Silver, P.A. 2003. Genome-wide analysis of RNA-protein interactions illustrates specificity of the mRNA export machinery. Nat. Genet. 33: 155-161. 
Hieronymus, H., Yu, M.C., and Silver, P.A. 2004. Genome-wide mRNA surveillance is coupled to mRNA export. Genes \& Dev. 18: 2652-2662.

Hofmann, K. and Bucher, P. 1998. The PCI domain: A common theme in three multiprotein complexes. Trends Biochem. Sci. 23: 204-205.

Hu, D., Mayeda, A., Trembley, J.H., Lahti, J.M., and Kidd, V.J. 2003. CDK11 complexes promote pre-mRNA splicing. $J$. Biol. Chem. 278: 8623-8629.

Huang, X. 1994. On global sequence alignment. Comput. Appl. Biosci. 10: 227-235.

Huang, Y., Gattoni, R., Stevenin, J., and Steitz, J.A. 2003. SR splicing factors serve as adapter proteins for TAP-dependent mRNA export. Mol. Cell 11: 837-843.

Huang, Y., Yario, T.A., and Steitz, J.A. 2004. A molecular link between SR protein dephosphorylation and mRNA export. Proc. Nat1. Acad. Sci. 101: 9666-9670.

Kapadia, F., Pryor, A., Chang, T.H., and Johnson, L.F. 2006. Nuclear localization of poly $(\mathrm{A})^{+}$mRNA following siRNA reduction of expression of the mammalian RNA helicases UAP56 and URH49. Gene 384: 37-44.

Katahira, J., Strasser, K., Podtelejnikov, A., Mann, M., Jung, J.U., and Hurt, E. 1999. The Mex67p-mediated nuclear mRNA export pathway is conserved from yeast to human. EMBO $J$. 18: 2593-2609.

Kedersha, N., Chen, S., Gilks, N., Li, W., Miller, I.J., Stahl, J., and Anderson, P. 2002. Evidence that ternary complex (eIF2GTP-tRNA(i)(Met))-deficient preinitiation complexes are core constituents of mammalian stress granules. Mol. Biol. Cell 13: 195-210.

Kiger, A.A., Baum, B., Jones, S., Jones, M.R., Coulson, A., Echeverri, C., and Perrimon, N. 2003. A functional genomic analysis of cell morphology using RNA interference. J. Biol. 2: 27. doi: 10.1186/1475-4924-2-27.

Kim Guisbert, K., Duncan, K., Li, H., and Guthrie, C. 2005. Functional specificity of shuttling hnRNPs revealed by genome-wide analysis of their RNA binding profiles. RNA 11: 383-393.

Kulkarni, M.M., Booker, M., Silver, S.J., Friedman, A., Hong, P., Perrimon, N., and Mathey-Prevot, B. 2006. Evidence of offtarget effects associated with long dsRNAs in Drosophila melanogaster cell-based assays. Nat. Methods 3: 833-838.

Lei, E.P. and Silver, P.A. 2002. Intron status and 3 '-end formation control cotranscriptional export of mRNA. Genes \& Dev. 16: 2761-2766.

Lei, E.P., Krebber, H., and Silver, P.A. 2001. Messenger RNAs are recruited for nuclear export during transcription. Genes \& Dev. 15: 1771-1782.

Libri, D., Graziani, N., Saguez, C., and Boulay, J. 2001. Multiple roles for the yeast SUB2/yUAP56 gene in splicing. Genes \& Dev. 15: 36-41.

Livak, K.J. and Schmittgen, T.D. 2001. Analysis of relative gene expression data using real-time quantitative PCR and the 2(- $-\Delta \Delta \mathrm{C}(\mathrm{T}))$ method. Methods 25: 402-408.

Longman, D., Johnstone, I.L., and Caceres, J.F. 2003. The Ref/ Aly proteins are dispensable for mRNA export and development in Caenorhabditis elegans. RNA 9: 881-891.

Luo, M.J. and Reed, R. 1999. Splicing is required for rapid and efficient mRNA export in metazoans. Proc. Natl. Acad. Sci. 96: $14937-14942$.

Moore, M.J., Schwartzfarb, E.M., Silver, P.A., and Yu, M.C. 2006. Differential recruitment of the splicing machinery during transcription predicts genome-wide patterns of mRNA splicing. Mol. Cell 24: 903-915.

Needleman, S.B. and Wunsch, C.D. 1970. A general method applicable to the search for similarities in the amino acid sequence of two proteins. J. Mol. Biol. 48: 443-453.

Park, J.W., Parisky, K., Celotto, A.M., Reenan, R.A., and Graveley, B.R. 2004. Identification of alternative splicing regulators by RNA interference in Drosophila. Proc. Natl. Acad. Sci. 101: 15974-15979.

Penkett, C.J., Morris, J.A., Wood, V., and Bahler, J. 2006. YOGY: A web-based, integrated database to retrieve protein orthologs and associated Gene Ontology terms. Nucleic Acids Res. 34: W330-W334. doi: 10.1093/nar/gk1311.

Pillai, S., Silventoinen, V., Kallio, K., Senger, M., Sobhany, S., Tate, J., Velankar, S., Golovin, A., Henrick, K., Rice, P., et al. 2005. SOAP-based services provided by the European Bioinformatics Institute. Nucleic Acids Res. 33: W25-W28. doi: 10.1093/nar/gki491.

Pollastri, G., Przybylski, D., Rost, B., and Baldi, P. 2002. Improving the prediction of protein secondary structure in three and eight classes using recurrent neural networks and profiles. Proteins 47: 228-235.

Reed, R. 2003. Coupling transcription, splicing and mRNA export. Curr. Opin. Cell Biol. 15: 326-331.

Reed, R. and Cheng, H. 2005. TREX, SR proteins and export of mRNA. Curr. Opin. Cell Biol. 17: 269-273.

Rehwinkel, J., Herold, A., Gari, K., Kocher, T., Rode, M., Ciccarelli, F.L., Wilm, M., and Izaurralde, E. 2004. Genomewide analysis of mRNAs regulated by the THO complex in Drosophila melanogaster. Nat. Struct. Mol. Biol. 11: 558566.

Saguez, C., Olesen, J.R., and Jensen, T.H. 2005. Formation of export-competent mRNP: Escaping nuclear destruction. Curr. Opin. Cell Biol. 17: 287-293.

Sakharkar, M.K. and Kangueane, P. 2004. Genome SEGE: A database for 'intronless' genes in eukaryotic genomes. BMC Bioinformatics 5: 67. doi: 10.1186/1471-2105-5-67.

Sanford, J.R., Gray, N.K., Beckmann, K., and Caceres, J.F. 2004. A novel role for shuttling SR proteins in mRNA translation. Genes \& Dev. 18: 755-768.

Segref, A., Sharma, K., Doye, V., Hellwig, A., Huber, J., Luhrmann, R., and Hurt, E. 1997. Mex67p, a novel factor for nuclear mRNA export, binds to both poly $(\mathrm{A})^{+}$RNA and nuclear pores. EMBO I. 16: 3256-3271.

Sommer, P. and Nehrbass, U. 2005. Quality control of messenger ribonucleoprotein particles in the nucleus and at the pore. Curr. Opin. Cell Biol. 17: 294-301.

Stevens, S.W., Ryan, D.E., Ge, H.Y., Moore, R.E., Young, M.K., Lee, T.D., and Abelson, J. 2002. Composition and functional characterization of the yeast spliceosomal penta-snRNP. Mol. Cell 9: 31-44.

Stothard, P. 2000. The sequence manipulation suite: JavaScript programs for analyzing and formatting protein and DNA sequences. Biotechniques 28: 1102, 1104.

Strasser, K. and Hurt, E. 2000. Yralp, a conserved nuclear RNAbinding protein, interacts directly with Mex67p and is required for mRNA export. EMBO J. 19: 410-420.

Strasser, K. and Hurt, E. 2001. Splicing factor Sub2p is required for nuclear mRNA export through its interaction with Yralp. Nature 413: 648-652.

Strasser, K., Bassler, J., and Hurt, E. 2000. Binding of the Mex67p/Mtr2p heterodimer to FXFG, GLFG, and FG repeat nucleoporins is essential for nuclear mRNA export. I. Cell Biol. 150: 695-706.

Stutz, F., Bachi, A., Doerks, T., Braun, I.C., Seraphin, B., Wilm, M., Bork, P., and Izaurralde, E. 2000. REF, an evolutionary conserved family of hnRNP-like proteins, interacts with TAP/Mex67p and participates in mRNA nuclear export. RNA 6: 638-650.

Swartz, J.E., Bor, Y.C., Misawa, Y., Rekosh, D., and Hammar- 
Farny et al.

skjold, M.L. 2007. The shuttling SR protein 9G8 plays a role in translation of unspliced mRNA containing a constitutive transport element. J. Biol. Chem. 282: 19844-19853.

Tan, W., Zolotukhin, A.S., Bear, J., Patenaude, D.J., and Felber, B.K. 2000. The mRNA export in Caenorhabditis elegans is mediated by Ce-NXF-1, an ortholog of human TAP/NXF and Saccharomyces cerevisiae Mex67p. RNA 6: 1762-1772.

van Deursen, J., Boer, J., Kasper, L., and Grosveld, G. 1996. G2 arrest and impaired nucleocytoplasmic transport in mouse embryos lacking the proto-oncogene CAN/Nup214. EMBO J. 15: 5574-5583.

Vasudevan, S. and Peltz, S.W. 2003. Nuclear mRNA surveillance. Curr. Opin. Cell Biol. 15: 332-337.

Vinciguerra, P. and Stutz, F. 2004. mRNA export: An assembly line from genes to nuclear pores. Curr. Opin. Cell Biol. 16: 285-292.

Watkins, J.L., Murphy, R., Emtage, J.L., and Wente, S.R. 1998. The human homologue of Saccharomyces cerevisiae Glelp is required for poly(A) ${ }^{+}$RNA export. Proc. Nat1. Acad. Sci. 95: 6779-6784.

Wiegand, H.L., Coburn, G.A., Zeng, Y., Kang, Y., Bogerd, H.P., and Cullen, B.R. 2002. Formation of Tap/NXT1 heterodimers activates Tap-dependent nuclear mRNA export by enhancing recruitment to nuclear pore complexes. Mol. Cell. Biol. 22: 245-256.

Windgassen, M., Sturm, D., Cajigas, I.J., Gonzalez, C.I., Seedorf, M., Bastians, H., and Krebber, H. 2004. Yeast shuttling SR proteins Npl3p, Gbp2p, and Hrb1p are part of the translating mRNPs, and Npl3p can function as a translational repressor. Mol. Cell. Biol. 24: 10479-10491.

Yu, M.C., Bachand, F., McBride, A.E., Komili, S., Casolari, J.M., and Silver, P.A. 2004. Arginine methyltransferase affects interactions and recruitment of mRNA processing and export factors. Genes \& Dev. 18: 2024-2035.

Zenklusen, D., Vinciguerra, P., Wyss, J.C., and Stutz, F. 2002. Stable mRNP formation and export require cotranscriptional recruitment of the mRNA export factors Yralp and Sub2p by Hpr1p. Mol. Cell. Biol. 22: 8241-8253.

Zhou, Z., Luo, M.J., Straesser, K., Katahira, J., Hurt, E., and Reed, R. 2000. The protein Aly links pre-messenger-RNA splicing to nuclear export in metazoans. Nature 407: 401405. 


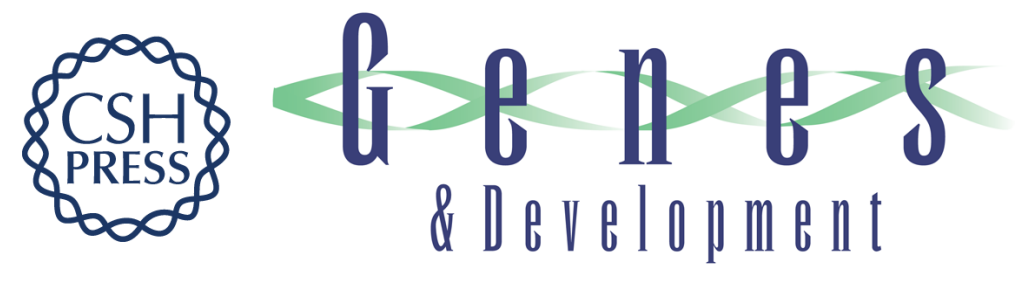

\title{
Definition of global and transcript-specific mRNA export pathways in metazoans
}

\author{
Natalie G. Farny, Jessica A. Hurt and Pamela A. Silver
}

Genes Dev. 2008, 22: originally published online December 17, 2007

Access the most recent version at doi:10.1101/gad.1616008

\section{Supplemental http://genesdev.cshlp.org/content/suppl/2007/12/18/gad.1616008.DC1 Material}

References This article cites 71 articles, 41 of which can be accessed free at: http://genesdev.cshlp.org/content/22/1/66.full.html\#ref-list-1

\section{License}

Email Alerting

Receive free email alerts when new articles cite this article - sign up in the box at the top Service

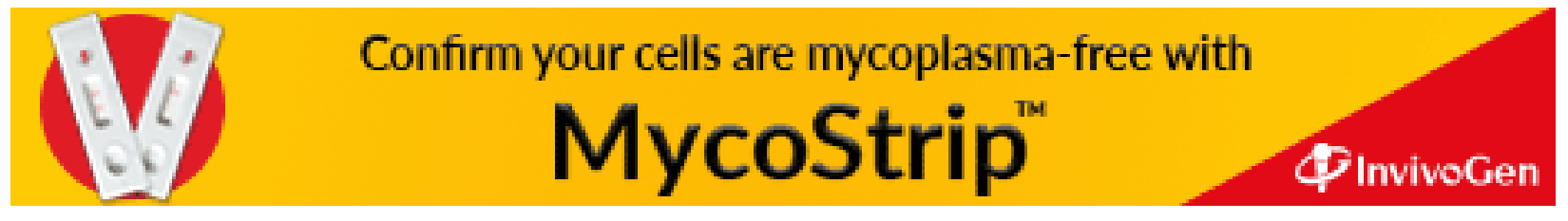

